\title{
An Analytical Step-by-Step Procedure to Derive the Flexural Response of RC Sections in Compression
}

\author{
Piero Colajanni, ${ }^{1}$ Marinella Fossetti, ${ }^{2}$ and Maurizio Papia ${ }^{3}$ \\ ${ }^{1}$ Dipartimento di Ingegneria Civile, Università di Messina, Contrada Di Dio, 98166 Messina, Italy \\ ${ }^{2}$ Facoltà di Ingegneria, Architettura e Scienze Motorie, Università Kore di Enna, Cittadella Universitaria, 94100 Enna, Italy \\ ${ }^{3}$ Dipartimento di Ingegneria Civile, Ambientale, Aerospaziale, dei Materiali, Università di Palermo, Viale delle Scienze, \\ 90128 Palermo, Italy
}

Correspondence should be addressed to Maurizio Papia; maurizio.papia@unipa.it

Received 6 March 2013; Revised 5 August 2013; Accepted 8 August 2013

Academic Editor: Andreas Kappos

Copyright (C) 2013 Piero Colajanni et al. This is an open access article distributed under the Creative Commons Attribution License, which permits unrestricted use, distribution, and reproduction in any medium, provided the original work is properly cited.

This paper proposes an analysis procedure able to determine the flexural response of rectangular symmetrically reinforced concrete sections subjected to axial load and uniaxial bending. With respect to the usual numerical approaches, based on the fibre decomposition method, this procedure is based on the use of analytical expressions of the contributions to the equilibrium given by the longitudinal reinforcement and the concrete region in compression, which depend on the neutral axis depth and the curvature at each analysis step. The formulation is developed in dimensionless terms, after a preliminary definition of the geometrical and mechanical parameters involved, so that the results are valid for classes of RC sections. The constitutive laws of the materials include confinement effect on the concrete and postyielding behaviour of the steel reinforcement, which can be assumed to be softening behaviour for buckled reinforcing bars. The strength and curvature domains at the first yielding of the reinforcement in tension and at the ultimate state are derived in the form of analytical curves depending on the compression level; therefore, the role of a single parameter on the shape of these curves can easily be deduced. The procedure is validated by comparing some results with those numerically obtained by other authors.

\section{Introduction}

The performance of reinforced concrete frames under severe earthquakes largely depends on the ability of the beam and column sections to undergo large inelastic deformations. Especially, this ability plays a decisive role in existing buildings, the safety level of which can be estimated by employing nonlinear analysis tools (like pushover), needing a careful input in terms of strength domains and moment-curvature relationships of the critical sections.

The evaluation of the moment-curvature response of critical sections of RC members is a complex issue mainly because of the interaction of various parameters: constitutive laws of materials in the elastic and plastic ranges, member geometry, buckling phenomena in reinforcing steel bars, and loading conditions.

In order to include in a computer software the cross-section strength domain and moment-curvature relationships of reinforced concrete members, two different approaches are usually followed: the use of strength domains [1-3] and moment-curvature relationships of a usually bilinear or trilinear prefixed shape [4-6], in which a degrading stiffness model reproduces the effect of yielding and damage of materials; the layered section approach, based on the fibre decomposition method [7-9].

The layered section approach gives a realistic and almost complete description of the behaviour of the critical regions of a RC framed structure, also allowing to include the bond slip effects in the moment-rotation response. However, the application of this approach to large structures with many degrees of freedom has some limitations, because numerical integrations and a prediction of the state of materials must be carried out considering the entire layers of each region where a plastic hinge can occur; thus, a high amount of information is required to characterize each section involved, and a large number of numerical operations is needed to reach an acceptable level of error. This results in heavy computational efforts and convergence problems for nonlinear structural analysis. 
Consequently, the use of moment-curvature relationships is still the more widespread and efficient approach.

The definition of moment-curvature relationships of $\mathrm{RC}$ sections has been a point of research interest for many years $[10,11]$. Many analytical and numerical techniques have been proposed, including several phenomena that affect the response of reinforced concrete elements.

Historically, moment-curvature relationships with softening branch were first introduced by Wood [12]. Mo [13] suggested a classical approach to reproduce the momentcurvature relationship including the softening branch, based on an FE analysis of the elastic-plastic buckling of the longitudinal reinforcement. An alternative approach was proposed in [14], where, by using a simplified model, complex nonlinear geometric effects were embedded in the nonlinear material behaviour of the cross-section. Chandrasekaran et al. [15] proposed an analytical relationship providing in explicit form the moment-curvature response of a section, by considering nonlinear constitutive laws of materials, chosen in accordance with the European technical codes, which can be applied by the use of a spreadsheet.

Commercial structural analysis software programs now provide the analyst with the option of conducting momentcurvature analyses at critical sections. Although well-verified equations have been used in the software developments, some questions may remain: (i) for a given project, how can the computational analysis results be easily verified outside the software? (ii) how can general considerations on the role of different parameters characterizing the section and reinforcement geometry be derived?

To answer to these questions, a dimensionless formulation is required, able to fully characterize the nonlinear behaviour of an RC cross-section subjected to an assigned loading condition.

In a recent paper [16], the behaviour of RC rectangular cross-sections under axial load and biaxial bending is examined in dimensionless terms. This paper confirms that the values of the ultimate bending moment and curvature in any direction can be efficiently related to the values corresponding to two separate conditions of uniaxial bending.

In this context the present paper proposes an analytical model for the evaluation of the moment-curvature relationship of rectangular RC sections subjected to axial load and uniaxial bending, by using an incremental strain technique, which could be an alternative to the classical fibre decomposition method. The model is based on a cross-sectional analysis satisfying strain compatibility and equilibrium conditions and can be utilized assuming any constitutive law for the confined concrete. The model is able to take into account several mechanical and geometrical parameters, such as section aspect ratio, longitudinal reinforcement amount and distribution, confinement effect on the concrete core, reinforcing steel hardening, and/or softening postbuckling behaviour. The formulation is carried out in dimensionless form, and it is able to stress the role of the aforementioned parameters in determining the shape of the moment-curvature relationship and the ultimate values of the bending moment and curvature.

The ability to analyze this role for classes of RC sections is the main contribution of the formulation proposed. On the other hand, the following limits are related to the basic assumptions: the model is applicable only to rectangular sections with symmetrical distribution of the longitudinal reinforcement; no cyclic behaviour is considered. Moreover, the use of the proposed model to define the moment-rotation response of the critical region to which the section considered ideally belongs requires a suitable modeling of the potential "plastic hinges" which is not discussed here.

\section{Analysis Model and Geometric Parameters}

The analysis model adopted is an updated version of that already utilized in [17], where analytical expressions of the ultimate moment and the corresponding compression level were provided for a class of sections more restricted than the one considered in the present paper.

The compressed concrete rectangular section is assumed to be reinforced by longitudinal steel bars symmetrically located with respect to the two principal axes of inertia of the section so that the geometrical and mechanical barycentres are coincident. lows:

The longitudinal reinforcing bars are distributed as fol-

(i) four bars of the same diameter are located at the corners, giving total sectional area $A_{s c}$;

(ii) $n_{b}$ bars of the same diameter, having total area $A_{s b}$, are located on the upper and lower parts of the section between the corner bars, in the direction parallel to the width;

(iii) $n_{h}$ bars of the same diameter, having total area $A_{s h}$, are located on the right and on the left between the corner bars, in the direction parallel to the height of the section.

Figure 1 shows the section geometry, the reinforcing bar location, and the analysis model adopted. The confined concrete core, of width $b$ and height $h$, is measured inside the stirrup perimeter; nevertheless, in some applications, in agreement with some technical codes, the resisting section of the concrete core is assumed to be defined by the axis line of the perimeter stirrups.

The symbols $c_{v}$ and $c_{o}$ in Figure 1(a) indicate the concrete cover depths, that is, the distances of the horizontal and vertical edges of the core from the external perimeter of the section.

These quantities had not been defined in the original model [17], because at the ultimate state the contribution of the concrete cover to the bearing capacity of the section is negligible.

The mean distance of the barycentres of the sectional area of the upper and lower reinforcing bars from the nearest horizontal side of the core, of length $b$, is denoted as $h_{1}$.

By assuming that the bending moment lies in the barycentric vertical plane of the section, the upper and lower reinforcing bars provide a primary contribution to the rotational equilibrium of the section, while the intermediate bars, distributed with constant pitch $p_{\ell}$ between the corner bars in the direction parallel to the height of the section, give a minor 


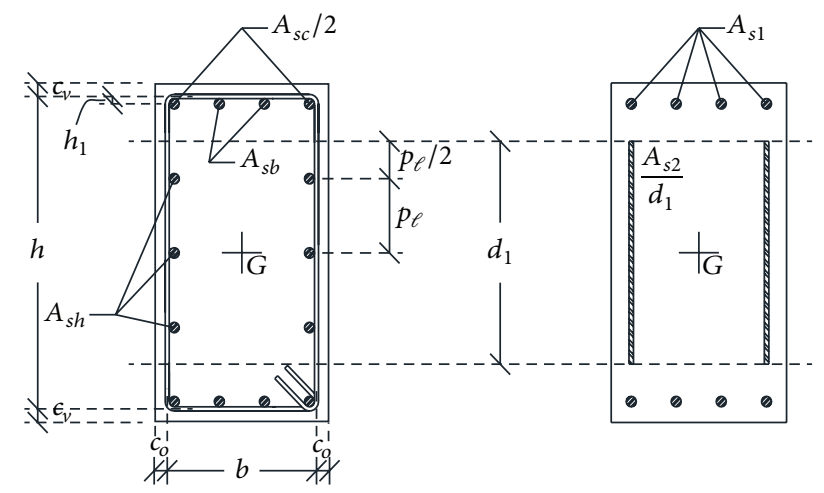

(a)

FIGURE 1: Section geometry and analysis model.

contribution. Consequently, the upper and lower reinforcing bars and the intermediate reinforcing bars will be conventionally denoted as "principal reinforcement" and "secondary reinforcement," respectively.

With reference to the symbols in Figure 1(b), the following relationships must be considered:

$$
\begin{aligned}
& A_{s 1}=\frac{A_{s c}}{2}+A_{s b}, \quad A_{s 2}=A_{s h} \\
& p_{\ell}=\frac{h-2 h_{1}}{n_{h}+1}, \quad d_{1}=n_{h} p_{\ell} .
\end{aligned}
$$

Figure 1(b) shows that in the analysis model, the secondary reinforcement is assumed to be uniformly distributed along the segment $d_{1}$ defined as shown in Figure 1(a).

Since high curvature values are involved (ultimate limit state), unconfined concrete spalling reduces the resisting section to that of the confined concrete core; all the geometrical and mechanical parameters involved in the formulation proposed here are referred to this reduced section.

Therefore, the axial load $N$ and bending moment $M$ will be normalized to the values

$$
N_{o}=b h f_{\mathrm{cco}}, \quad M_{o}=b h^{2} f_{\mathrm{cco}},
$$

where $f_{\text {cco }}$ is the cylindrical strength of the confined concrete.

The strains of the confined concrete and the dimensionless curvature $\varphi h$ will be normalized with respect to the strain $\varepsilon_{\mathrm{cco}}$ corresponding to $f_{\mathrm{cco}}$, and this normalization is indicated by using the superscription $(\sim)$; the same notation is adopted for the normalization of the strains of the unconfined concrete with respect to the strain $\varepsilon_{\mathrm{co}}$ corresponding to the cylindrical strength $f_{\mathrm{co}}$. The distances normalized to the height $h$ of the concrete core are denoted by using the superscription $\left(^{-}\right)$.

For clarity's sake, the geometrical parameters that must be considered assigned are denoted using Greek letters. Therefore, with reference to the symbols in Figure 1, the following geometrical parameters are defined here:

$$
\begin{gathered}
\delta_{v}=\frac{c_{v}}{h}, \quad \delta_{o}=\frac{c_{o}}{b}, \\
\lambda=\frac{h_{1}}{h}, \quad \alpha=\frac{d_{1}}{h}=\frac{n_{h}}{n_{h}+1}(1-2 \lambda) .
\end{gathered}
$$

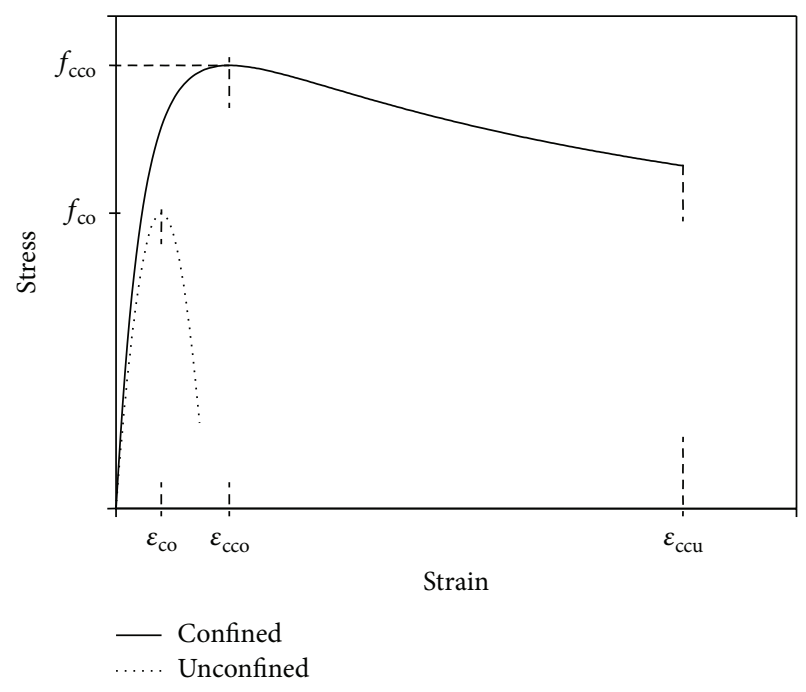

FIGURE 2: Constitutive laws of concrete.

\section{Constitutive Laws}

3.1. Concrete. Differently from what was necessary for the analysis at the ultimate state [17], to derive the entire momentcurvature curve of the class of RC sections under consideration, the constitutive law of the concrete must be defined for both the concrete core and the unconfined cover.

Figure 2 shows typical shapes of constitutive laws of concrete and the symbols adopted for the characteristic values of strains and stresses. Several analytical relations, expressing these laws and confirmed by experimental investigations, are available in the literature.

The formulation proposed in the present work allows the use of any law; however, the applications were carried out using the expressions proposed in [18], which also prove to be valid for eccentric compression and fibrous and/or highstrength concrete [19-22].

In normalized form these expressions are written as

$$
\begin{array}{cc}
s_{c}(\widetilde{\mathcal{\varepsilon}})=\left(2 \widetilde{\mathcal{\varepsilon}}-\widetilde{\mathcal{\varepsilon}}^{2}\right)^{\beta}, & 0 \leq \widetilde{\mathcal{\varepsilon}} \leq 1, \\
s_{c}(\widetilde{\mathcal{\varepsilon}})=1+\eta(\widetilde{\mathcal{\varepsilon}}-1), & 1 \leq \widetilde{\mathcal{\varepsilon}} \leq \mu,
\end{array}
$$

where $s_{c}$ is the current stress value normalized to the cylindrical strength and $\widetilde{\varepsilon}$ the strain normalized to the corresponding strain ( $\varepsilon_{\mathrm{co}}$ or $\varepsilon_{\mathrm{cco}}$ for unconfined or confined concrete, resp.). The exponent $\beta \leq 1$ governs the shape of the ascending branch of the constitutive law. The parameter $\eta$ rules the negative slope of the linear postpeak branch and is obtained by normalizing the value of the softening modulus $E_{c, \text { soft }}$ in the dimensional plane $f_{c}-\varepsilon_{c}$ with respect to the secant modulus, expressed by the ratio between the cylindrical strength and the corresponding strain.

The symbol $\mu$ indicates the normalized value of the ultimate concrete strain and is an index of the available "ductility" of the material.

Equations (4) and (5) are valid both for unconfined and confined concrete upon calibration of the parameters $\beta, \eta$, and $\mu$. 
All quantities referring to the unconfined concrete are here denoted by the subscript ()$_{c}$; the ascending branch is modelled by assuming the value $\beta_{c}=1$ so that for $\varepsilon_{\mathrm{co}}=0.002$ (4) expresses the parabolic law first proposed in [23] and subsequently adopted by several researchers. Considering that the softening branch is very steep, for unconfined concrete one sets $\eta_{c}=-0.8$, so that (5) provides $f_{c}=0$ for $\varepsilon_{c}=\varepsilon_{\mathrm{cu}}=$ $0.0045\left(\mu_{c}=2.25\right)$.

For confined concrete, the characteristic quantities of which are denoted by the subscript ()$_{c c}$, the parameters $\beta_{c c}$ e $\eta_{c c}$ depend on the effective confinement pressure and can be calculated by the procedure proposed in [18]. The available ductility $\mu_{\mathrm{cc}}=\varepsilon_{\mathrm{ccu}} / \varepsilon_{\mathrm{cco}}$ is obtained by imposing a conventional limit value of reduction to the postpeak strength with respect to the peak value, or by assuming the ultimate strain $\varepsilon_{\text {ccu }}$ in agreement with expressions validated experimentally $[24,25]$.

In the present formulation, the factors relating the cylindrical strength and the corresponding strain of the confined concrete to the ones of the originally unconfined concrete are denoted as

$$
k_{1}=\frac{f_{\mathrm{cco}}}{f_{\mathrm{co}}}, \quad k_{2}=\frac{\varepsilon_{\mathrm{cco}}}{\varepsilon_{\mathrm{co}}} .
$$

Moreover, the following integral functions are defined:

$$
S_{1, \widetilde{\varepsilon}}=\int_{0}^{\widetilde{\varepsilon}} s_{c}(\widetilde{\mathcal{\varepsilon}}) d \widetilde{\mathcal{\varepsilon}}, \quad S_{2, \widetilde{\varepsilon}}=\int_{0}^{\widetilde{\varepsilon}} s_{c}(\widetilde{\mathcal{\varepsilon}}) \widetilde{\varepsilon} d \widetilde{\varepsilon} .
$$

Equations (4) and (5) show that these integrals can be expressed in an exact analytical form only if $\beta=1$ (unconfined concrete). Therefore, numerical analyses were carried out, in order to derive approximate analytical expressions for the confined concrete to be utilized in practical applications.

As a result, it can be shown that in the field $0.4 \leq \beta \leq 1$, which includes all real cases, the following expressions imply a maximum error of $8 \%$ with respect to the values calculated by numerical integration, for $\widetilde{\varepsilon} \geq 0.1$ :

$$
\begin{array}{r}
S_{1, \widetilde{\varepsilon}}=\left(\widetilde{\mathcal{E}}^{2}-\frac{1}{3} \widetilde{\mathcal{\varepsilon}}^{3}\right)^{r_{1}}, \quad S_{2, \widetilde{\varepsilon}}=\left(\frac{2}{3} \widetilde{\mathcal{E}}^{3}-\frac{1}{4} \widetilde{\mathcal{E}}^{4}\right)^{r_{2}}, \\
0.1 \leq \widetilde{\mathcal{\varepsilon}} \leq 1,
\end{array}
$$

where

$$
r_{1}=0.76+0.48(\beta-0.5), \quad r_{2}=0.87+0.26(\beta-0.5) .
$$

On the other hand, the analytical form expressed by (5) shows that (7) can be exactly integrated in the field of the normalized postpeak strains:

$$
\begin{array}{r}
S_{1, \widetilde{\varepsilon}}=S_{1,1}+(\widetilde{\varepsilon}-1)+\frac{1}{2} \eta(\widetilde{\varepsilon}-1)^{2}, \\
S_{2, \widetilde{\varepsilon}}=S_{2,1}+\frac{1}{2}\left(\widetilde{\varepsilon}^{2}-1\right)+\frac{1}{6} \eta(\widetilde{\varepsilon}-1)^{2}(1+2 \widetilde{\varepsilon}), \\
1 \leq \widetilde{\varepsilon} \leq \mu .
\end{array}
$$

These expressions also provide approximate values for confined concrete, because of the approximation by which

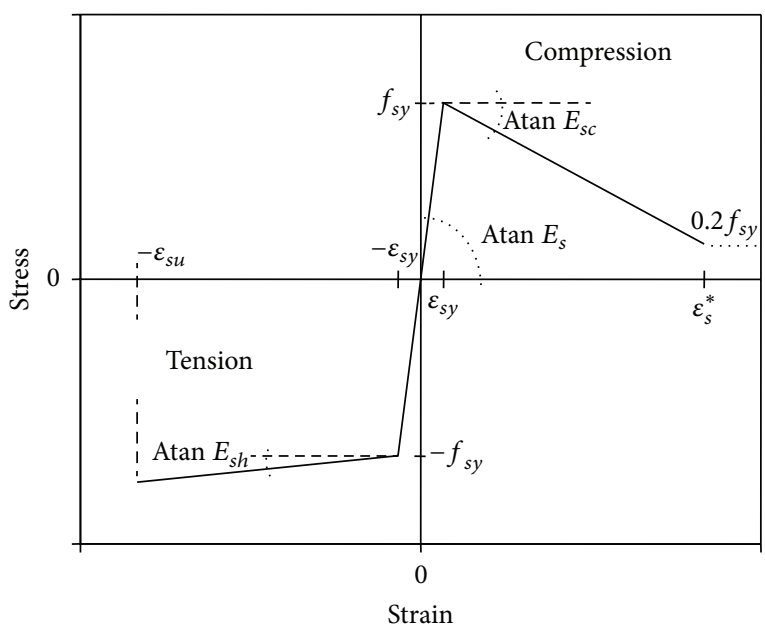

FIGURE 3: Constitutive law of longitudinal steel reinforcement.

the addends $S_{1,1}$ and $S_{2,1}$ are affected while for $\beta=1$ (unconfined concrete) (9) give $r_{1}=r_{2}=1$, and both (8) and (10) express the integral quantities (7) in the exact analytical form.

3.2. Longitudinal Steel Reinforcement. Figure 3 shows the bilinear simplified constitutive law adopted for the longitudinal steel bars in tension and compression, and the symbols denoting the characteristic quantities involved.

With respect to the analyses made in [17], the restrictive assumption that the postyielding modulus in compression must be the same as in tension is removed.

Under tension the possible hardening behaviour is defined by the mean hardening modulus $E_{s h}$; under compression the slope of the postyielding branch can be modified (this option is shown in the figure), so that it can become negative if the transverse reinforcement is not able to prevent buckling of the longitudinal bars. In this case, the slope of the postyielding branch is governed by the modulus $E_{s c}$, which can be determined by using the model proposed in [26], assuming that the ultimate strain corresponds to a reduction of $80 \%$ of the yielding stress $f_{s y}$. This ultimate strain in compression is denoted as $\varepsilon_{s}^{*}$ in Figure 3.

The simple equations that analytically express the laws of the elastic and postyielding branches in Figure 3 are here omitted for brevity's sake. They will be introduced in the course of the formulation.

The dimensionless parameters characterizing the slopes of the postyielding branches and the ultimate strain in an ideal normalized stress-strain diagram are denoted as

$$
\eta_{s h}=\frac{E_{s h}}{E_{s}}, \quad \eta_{s c}=\frac{E_{s c}}{E_{s}}, \quad \mu_{r}=\frac{\varepsilon_{s u}}{\varepsilon_{s y}},
$$

where $E_{s}$ is the Young modulus and $\varepsilon_{s y}, \varepsilon_{s u}$ are the yielding and ultimate strains, respectively. For compressed steel bars subject to buckling, $\varepsilon_{s u}$ is understood to be replaced by $\varepsilon_{s}^{*}$ in $(11)$.

A further parameter relating the characteristic strain values of steel and concrete is

$$
\zeta_{s, c}=\frac{\varepsilon_{s y}}{\varepsilon_{c c o}} .
$$


Finally, the amount of principal and secondary longitudinal reinforcement is related to the section of the concrete core by means of the mechanical ratios of reinforcement

$$
\omega_{1}=2 \frac{A_{s 1} f_{s y}}{b h f_{c c o}}, \quad \omega_{2}=2 \frac{A_{s 2} f_{s y}}{b h f_{c c o}} .
$$

\section{Equilibrium of Section}

Denoting as $N$ and $M$ the axial load and the bending moment acting on the section, and as

$$
n=\frac{N}{N_{o}}=\frac{N}{b h f_{\text {cco }}}, \quad m=\frac{M}{M_{o}}=\frac{M}{b h^{2} f_{\text {cco }}},
$$

these quantities normalized with respect to the ones defined by (2), the equilibrium of the section in dimensionless form is expressed by the following equations:

$$
\begin{gathered}
n=n_{s 1}+n_{s 2}+n_{c}, \\
m=m_{s 1}+m_{s 2}+m_{c} .
\end{gathered}
$$

At the second member of these equations there are clearly indicated and ordered contributions offered by the principal reinforcement, secondary reinforcement, and concrete.

These contributions are analytically expressed in the following sections by assuming the classical hypothesis that the section remains plane and neglecting the tensile concrete strength.

4.1. Contribution of Principal Reinforcement. In the analytical formulation shown in this section, the following parameters are involved: the geometrical parameter $\lambda$, defined in (1), the mechanical parameters characterizing the constitutive law of the steel reinforcement $\eta_{s c}, \eta_{s h}$, and $\zeta_{s, c}$, defined by (11) and (12), and the mechanical ratio of reinforcement $\omega_{1}$ expressed by the first of (13).

Figure 4 shows the lateral view of the RC member considered and a generic state of strain and stress.

By using the symbols shown in the figure, the upper and lower reinforcement bars are subjected, respectively, to the strains:

$$
\begin{gathered}
\varepsilon_{s a}=\varphi\left(x_{c}-h_{1}\right)=\varphi h\left[\left(\bar{x}_{c}-\frac{1}{2}\right)+\lambda_{1}\right], \\
\varepsilon_{s b}=\varphi\left(x_{c}-h+h_{1}\right)=\varphi h\left[\left(\bar{x}_{c}-\frac{1}{2}\right)-\lambda_{1}\right],
\end{gathered}
$$

where

$$
\bar{x}_{c}=\frac{x_{c}}{h}
$$

is the neutral axis depth normalized to the height $h$ of the section of concrete core and

$$
\lambda_{1}=\frac{1-2 \lambda}{2} \text {. }
$$

The corresponding stresses, denoted as $f_{s a}$ and $f_{s b}$ in Figure 3(c), can be expressed in the forms

$$
\begin{gathered}
f_{s a}=E_{s} \varepsilon_{s y}+E_{s c}\left(\varepsilon_{s a}-\varepsilon_{s y}\right), \\
f_{s b}=-E_{s} \varepsilon_{s y}+E_{s h}\left(\varepsilon_{s b}+\varepsilon_{s y}\right) .
\end{gathered}
$$

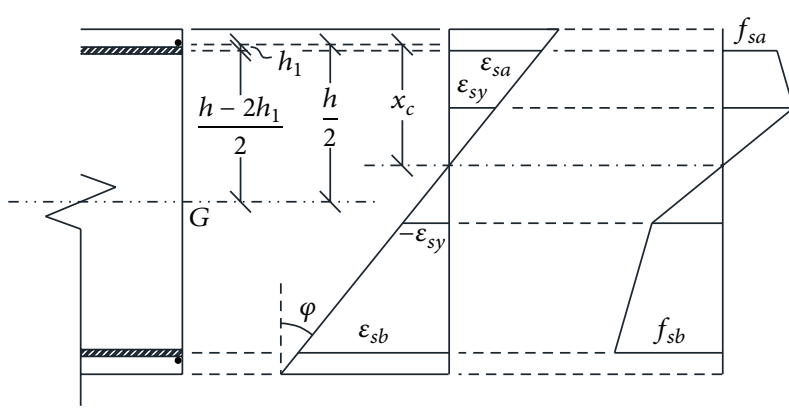

(a)

(b)

(c)

Figure 4: Strain and stress states of principal reinforcement of section.

It must be observed that (20) expresses the linear elastic behaviour of the upper reinforcement if in the field of strains $-\varepsilon_{s y} \leq \varepsilon_{s a} \leq \varepsilon_{s y}$ one sets $E_{s c}=E_{s}$; analogously, (21) expresses the elastic response of the lower reinforcement if for $-\varepsilon_{s y} \leq$ $\varepsilon_{s b} \leq \varepsilon_{s y}$ one sets $E_{s h}=E_{s}$.

The axial load and the bending moment that the principal reinforcement can bear with respect to the barycentre of the section are expressed by

$$
\begin{gathered}
N_{s 1}=A_{s 1}\left(f_{s a}+f_{s b}\right), \\
M_{s 1}=A_{s 1}\left(f_{s a}-f_{s b}\right)\left(\frac{h}{2}-h_{1}\right) .
\end{gathered}
$$

By substituting (17) into (20) and (21) and by introducing the resulting expressions of $f_{s a}$ and $f_{s b}$ into (22), in normalized form one obtains

$$
\begin{aligned}
n_{s 1}=\frac{\omega_{1}}{2}\left[\frac{\widetilde{\varphi}}{\zeta_{s, c}}\left(\bar{x}_{c}-\frac{1}{2}\right)\left(\eta_{s h}+\eta_{s c}\right)\right. & \\
+ & \left.\left(1-\frac{\widetilde{\varphi}}{\zeta_{s, c}} \lambda_{1}\right)\left(\eta_{s h}-\eta_{s c}\right)\right], \\
m_{s 1}=\frac{\omega_{1}}{2} \lambda_{1} & {\left[2-\frac{\widetilde{\varphi}}{\zeta_{s, c}}\left(\bar{x}_{c}-\frac{1}{2}\right)\left(\eta_{s h}-\eta_{s c}\right)\right.} \\
& \left.-\left(1-\frac{\widetilde{\varphi}}{\zeta_{s, c}} \lambda_{1}\right)\left(\eta_{s h}+\eta_{s c}\right)\right],
\end{aligned}
$$

where

$$
\widetilde{\varphi}=\frac{\varphi h}{\varepsilon_{\text {cco }}}
$$

is the dimensionless curvature, normalized with respect to $\varepsilon_{\text {cco }}$.

On the basis of what was observed commenting on (20) and (21), (23) and (24) have a general validity under the condition that one sets

$$
\begin{gathered}
\eta_{s c}=1, \quad \text { if }-1 \leq \frac{\widetilde{\varphi}}{\zeta_{s, c}}\left(\bar{x}_{c}-\lambda\right) \leq 1, \\
\eta_{s h}=1, \quad \text { if }-1 \leq \frac{\widetilde{\varphi}}{\zeta_{s, c}}\left(\bar{x}_{c}-1+\lambda\right) \leq 1 .
\end{gathered}
$$




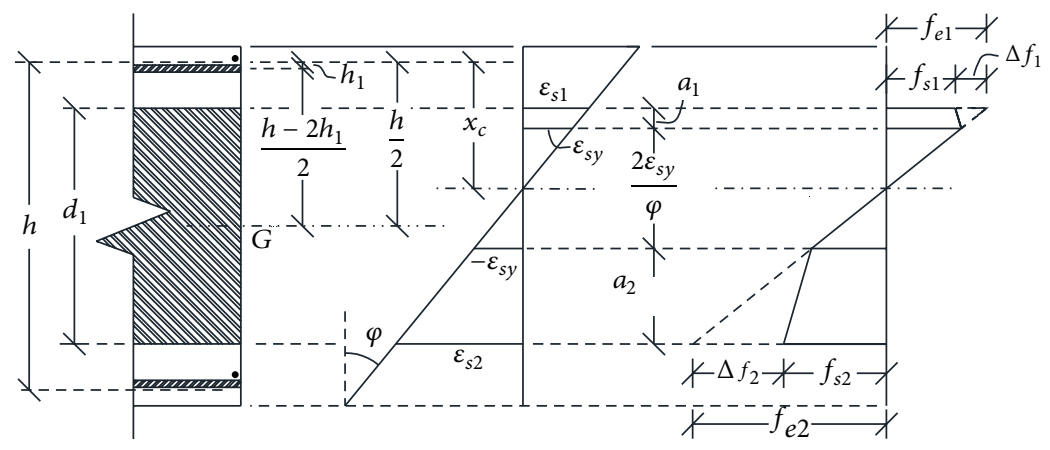

(a)

(b)

(c)

FIGURE 5: Strains and stresses of uniformly distributed secondary reinforcement.

4.2. Contribution of Secondary Reinforcement. With respect to the formulation shown in the previous section, instead of $\lambda$ and $\omega_{1}$ the parameters $\alpha$ and $\omega_{2}$ are now involved, which are expressed in (3) and (13), respectively.

Figure 5 shows the symbols used to define a generic strain state of the section and the corresponding stress state. From this figure one can deduce that the distances $a_{1}$ and $a_{2}$ can be expressed by

$$
a_{1}=\frac{d_{1}}{2}-\frac{h}{2}+x_{c}-\frac{\varepsilon_{s y}}{\varphi}, \quad a_{2}=\frac{d_{1}}{2}+\frac{h}{2}-x_{c}-\frac{\varepsilon_{s y}}{\varphi} .
$$

By normalizing these distances to the height $h$ and remembering the expression of the normalized dimensionless curvature (25), one obtains

$$
\begin{aligned}
& \bar{a}_{1}=\left(\frac{\alpha}{2}-\frac{\zeta_{s, c}}{\widetilde{\varphi}}\right)+\left(\bar{x}_{c}-\frac{1}{2}\right), \\
& \bar{a}_{2}=\left(\frac{\alpha}{2}-\frac{\zeta_{s, c}}{\tilde{\varphi}}\right)-\left(\bar{x}_{c}-\frac{1}{2}\right) .
\end{aligned}
$$

The actual stress at the upper "fibre" of the uniformly distributed secondary reinforcement, denoted as $f_{s 1}$ in Figure 5(c), can be expressed by separately evaluating the stress $f_{e 1}$ that one would have in the case of infinitely elastic behaviour and the difference $\Delta f_{1}$ due to the actual postyielding behaviour.

These quantities are expressed, respectively, by

$$
\begin{gathered}
f_{e 1}=E_{s} \varphi\left(a_{1}+\frac{\varepsilon_{s y}}{\varphi}\right)=f_{s y} \frac{\tilde{\varphi}}{\zeta_{s, c}}\left(\bar{a}_{1}+\frac{\zeta_{s, c}}{\widetilde{\varphi}}\right), \\
\Delta f_{1}=\left(E_{s}-E_{s c}\right) \varphi a_{1}=f_{s y} \frac{\widetilde{\varphi}}{\zeta_{s, c}}\left(1-\eta_{s c}\right) \bar{a}_{1} .
\end{gathered}
$$

Analogously, at the lower fibre of the secondary reinforcement one has

$$
\begin{aligned}
& f_{e 2}=-E_{s} \varphi\left(a_{2}+\frac{\varepsilon_{s y}}{\varphi}\right)=-f_{s y} \frac{\tilde{\varphi}}{\zeta_{s, c}}\left(\bar{a}_{2}+\frac{\zeta_{s, c}}{\widetilde{\varphi}}\right), \\
& \Delta f_{2}=-\left(E_{s}-E_{s h}\right) \varphi a_{2}=-f_{s y} \frac{\widetilde{\varphi}}{\zeta_{s, c}}\left(1-\eta_{s h}\right) \bar{a}_{2} .
\end{aligned}
$$

Then, the axial load and bending moment with respect to the barycentre of the section that the secondary reinforcement can bear can be calculated by the following expressions:

$$
\begin{aligned}
N_{s 2}=\frac{2 A_{s 2}}{d_{1}} \frac{h}{2}\left[f_{e 1}\left(\bar{a}_{1}+\frac{\zeta_{s, c}}{\widetilde{\varphi}}\right)+f_{e 2}\left(\bar{a}_{2}+\frac{\zeta_{s, c}}{\widetilde{\varphi}}\right)\right. & \left.-\left(\Delta f_{1} \bar{a}_{1}+\Delta f_{2} \bar{a}_{2}\right)\right], \\
M_{s 2}=\frac{2 A_{s 2}}{d_{1}} \frac{h^{2}}{2}[ & \left(f_{e 1}-f_{e 2}\right) \frac{\alpha^{2}}{6}-\Delta f_{1} \bar{a}_{1}\left(\frac{\alpha}{2}-\frac{\bar{a}_{1}}{3}\right) \\
& \left.+\Delta f_{2} \bar{a}_{2}\left(\frac{\alpha}{2}-\frac{\bar{a}_{2}}{3}\right)\right] .
\end{aligned}
$$

Equations (28), (29), and (31) show that

$$
\begin{gathered}
f_{e 1}\left(\bar{a}_{1}+\frac{\zeta_{s, c}}{\widetilde{\varphi}}\right)+f_{e 2}\left(\bar{a}_{2}+\frac{\zeta_{s, c}}{\widetilde{\varphi}}\right)=2 f_{s y} \frac{\widetilde{\varphi}}{\zeta_{s, c}}\left(\bar{x}_{c}-\frac{1}{2}\right) \alpha, \\
f_{e 1}-f_{e 2}=f_{s y} \frac{\widetilde{\varphi}}{\zeta_{s, c}} \alpha .
\end{gathered}
$$

Therefore, substituting (34) into (33), in normalized form one obtains

$$
\begin{aligned}
n_{s 2}= & \frac{N_{s 2}}{N_{o}} \\
= & \omega_{2} \frac{\tilde{\varphi}}{\zeta_{s, c}}\left\{\left(\bar{x}_{c}-\frac{1}{2}\right)-\frac{1}{2 \alpha}\right. \\
& \left.\times\left[\left(1-\eta_{s c}\right) \bar{a}_{1}^{2}-\left(1-\eta_{s h}\right) \bar{a}_{2}^{2}\right]\right\}, \\
m_{s 2}=\frac{M_{s 2}}{M_{o}} & \frac{\omega_{2}}{2 \alpha} \frac{\widetilde{\varphi}}{\zeta_{s, c}}\left[\frac{\alpha^{3}}{6}-\left(1-\eta_{s c}\right)\left(\frac{\alpha}{2}-\frac{\bar{a}_{1}}{3}\right) \bar{a}_{1}^{2}\right. \\
& \left.-\left(1-\eta_{s h}\right)\left(\frac{\alpha}{2}-\frac{\bar{a}_{2}}{3}\right) \bar{a}_{2}^{2}\right] .
\end{aligned}
$$




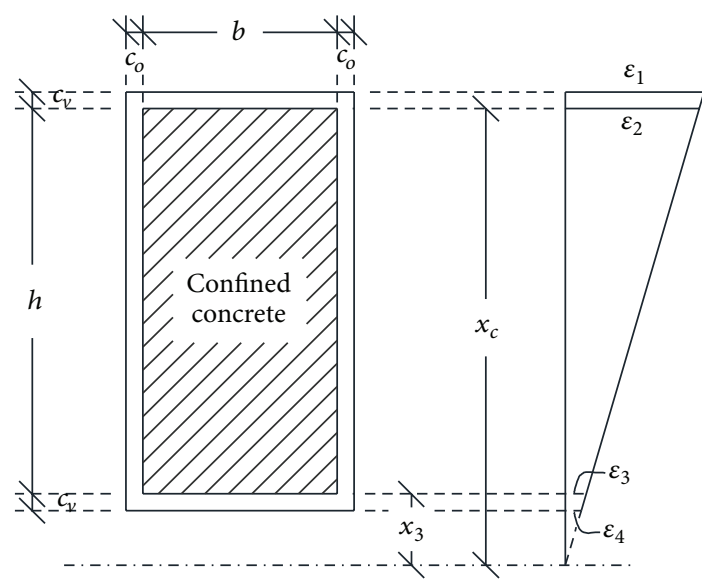

(a)

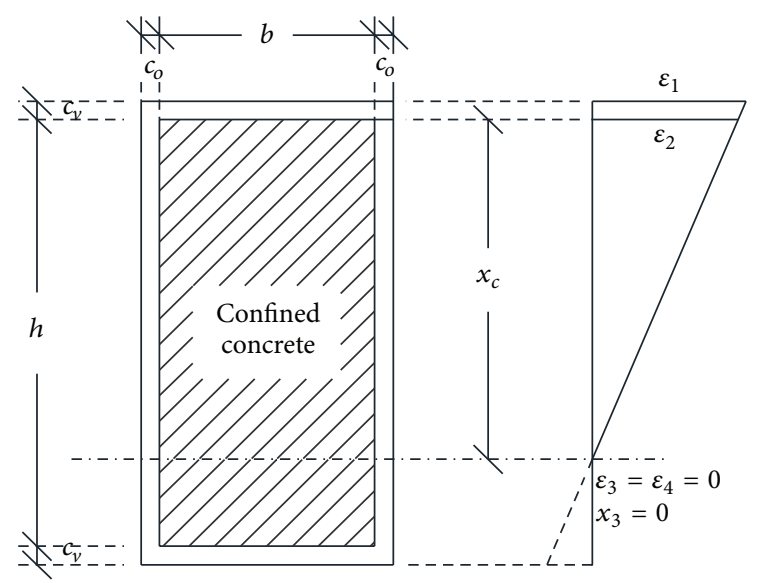

(b)

FIGURE 6: Strain state of concrete section: (a) uncracked section; (b) cracked section.

It must be observed that, if one sets $E_{s c}=E_{s}$ in (30) and/or $E_{s h}=E_{s}$ in (32), (33) expresses the contributions to the axial load and bending moment in the case in which the upper fibre and/or the lower fibre of the secondary reinforcement remain in the elastic field. As a consequence, (35) and (36) are valid for any value of $\bar{x}_{c}$ e $\widetilde{\varphi}$ under the condition that one sets

$$
\begin{aligned}
& \eta_{s c}=1, \quad \text { if }-\varepsilon_{s y} \leq \varepsilon_{s 1} \leq \varepsilon_{s y} \Longrightarrow-1 \leq \frac{\widetilde{\varphi}}{\zeta_{s, c}}\left(\bar{x}_{c}-\frac{1-\alpha}{2}\right) \leq 1, \\
& \eta_{s h}=1, \quad \text { if }-\varepsilon_{s y} \leq \varepsilon_{s 2} \leq \varepsilon_{s y} \Longrightarrow-1 \leq \frac{\widetilde{\varphi}}{\zeta_{s, c}}\left(\bar{x}_{c}-\frac{1+\alpha}{2}\right) \leq 1 .
\end{aligned}
$$

4.3. Contribution of Concrete. Figure 6 shows the strain states of the section corresponding to the cases of uncracked and cracked sections. By using the symbols in the figure, the contributions to the equilibrium provided by the concrete core are expressed by

$$
\begin{gathered}
N_{\mathrm{cc}}=b \int_{x_{3}}^{x_{c}} f_{c}(x) d x=\frac{b h f_{\mathrm{cco}}}{\widetilde{\varphi}} \int_{\widetilde{\varepsilon}_{3}}^{\widetilde{\varepsilon}_{2}} s_{c}(\widetilde{\varepsilon}) d \widetilde{\varepsilon}, \\
M_{\mathrm{cc}}=b \int_{x_{3}}^{x_{c}} f_{c}(x) x d x-N_{\mathrm{cc}}\left(x_{c}-\frac{h}{2}\right) \\
=b h^{2} f_{\mathrm{cco}}\left(\frac{1}{\widetilde{\varphi}^{2}} \int_{\widetilde{\varepsilon}_{3}}^{\widetilde{\varepsilon}_{2}} s_{c}(\widetilde{\varepsilon}) \widetilde{\varepsilon} d \widetilde{\varepsilon}-\frac{\bar{x}_{c}-0.5}{\widetilde{\varphi}} \int_{\widetilde{\varepsilon}_{3}}^{\tilde{\varepsilon}_{2}} s_{c}(\widetilde{\varepsilon}) d \widetilde{\varepsilon}\right),
\end{gathered}
$$

where

$$
x_{3}= \begin{cases}0 & \text { for } x_{c} \leq h \\ x_{c}-h & \text { for } x_{c}>h\end{cases}
$$

and consequently

$$
\widetilde{\varepsilon}_{2}=\widetilde{\varphi}_{c} \quad \widetilde{\varepsilon}_{3}= \begin{cases}0 & \text { for } \bar{x}_{c} \leq 1 \\ \widetilde{\varphi}\left(\bar{x}_{c}-1\right) & \text { for } \bar{x}_{c}>1 .\end{cases}
$$

Considering (7), in the normalized form one obtains

$$
\begin{gathered}
n_{\mathrm{cc}}=\frac{N_{\mathrm{cc}}}{N_{o}}=\frac{1}{\widetilde{\varphi}}\left(S_{1, \tilde{\varepsilon}_{2}}-S_{1, \widetilde{\varepsilon}_{3}}\right), \\
m_{\mathrm{cc}}=\frac{M_{\mathrm{cc}}}{M_{o}}=\frac{1}{\widetilde{\varphi}^{2}}\left(S_{2, \widetilde{\varepsilon}_{2}}-S_{2, \widetilde{\varepsilon}_{3}}\right)-n_{\mathrm{cc}}\left(\bar{x}_{\mathrm{c}}-\frac{1}{2}\right) .
\end{gathered}
$$

The contribution of the surrounding unconfined concrete (concrete cover) can be calculated by subtracting the contribution of the confined region to that of the whole section.

Considering that the strains involved in the functions $S_{1, \tilde{\varepsilon}}$ and $S_{2, \tilde{\varepsilon}}$ must be normalized with respect to the strain $\varepsilon_{\text {co }}$ (unconfined concrete); by following the same procedure as that leading to (41) and (42) and by introducing the confinement efficiency factors defined by (6), for the whole section one obtains

$$
\begin{gathered}
n_{\mathrm{un}, 1}=\frac{1+2 \delta_{o}}{k_{1}} \frac{1}{k_{2} \widetilde{\varphi}}\left(S_{1, \widetilde{\varepsilon}_{1}^{\prime}}-S_{1, \widetilde{\varepsilon}_{4}^{\prime}}\right), \\
m_{\mathrm{un}, 1}=\frac{1+2 \delta_{o}}{k_{1}} \frac{1}{\left(k_{2} \widetilde{\varphi}\right)^{2}}\left(S_{2, \widetilde{\varepsilon}_{1}^{\prime}}-S_{2, \widetilde{\varepsilon}_{4}^{\prime}}\right)-n_{\mathrm{un}, 1}\left(\bar{x}_{c}-\frac{1}{2}\right),
\end{gathered}
$$

where

$$
\begin{gathered}
\widetilde{\varepsilon}_{1}^{\prime}=k_{2} \widetilde{\varphi}\left(\bar{x}_{c}+\delta_{v}\right) \leq \mu_{c}, \\
\widetilde{\varepsilon}_{4}^{\prime}= \begin{cases}0 & \text { for } \bar{x}_{c} \leq\left(1+\delta_{v}\right) \\
k_{2} \widetilde{\varphi}\left[\bar{x}_{c}-\left(1+\delta_{v}\right)\right] & \text { for } \bar{x}_{c}>\left(1+\delta_{v}\right) .\end{cases}
\end{gathered}
$$

The contribution to be subtracted from the above quantities are calculated by modifying (41) and (42) in order to consider the different constitutive law of the unconfined concrete and the different base of normalization of strain and stress. It can easily be shown that one obtains

$$
\begin{gathered}
n_{\mathrm{un}, 2}=\frac{1}{k_{1} k_{2} \widetilde{\varphi}}\left(S_{1, \widetilde{\varepsilon}_{2}^{\prime}}-S_{1, \widetilde{\varepsilon}_{3}}\right), \\
m_{\mathrm{un}, 2}=\frac{1}{k_{1}\left(k_{2} \widetilde{\varphi}\right)^{2}}\left(S_{2, \tilde{\varepsilon}_{2}^{\prime}}-S_{2, \widetilde{\varepsilon}_{3}^{\prime}}\right)-n_{\mathrm{un}, 2}\left(\bar{x}_{c}-\frac{1}{2}\right),
\end{gathered}
$$


where

$$
\begin{gathered}
\widetilde{\varepsilon}_{2}^{\prime}=k_{2} \widetilde{\varphi}_{c} \leq \mu_{c}, \\
\widetilde{\varepsilon}_{3}^{\prime}= \begin{cases}0 & \text { for } \bar{x}_{c} \leq 1 \\
k_{2} \widetilde{\varphi}\left(\bar{x}_{c}-1\right) & \text { for } \bar{x}_{c}>1 .\end{cases}
\end{gathered}
$$

On the basis of what was said above, the effective contribution of the concrete section in compression in a generic loading state is expressed by

$$
\begin{gathered}
n_{c}=n_{\mathrm{cc}}+n_{\mathrm{un}, 1}-n_{\mathrm{un}, 2}, \\
m_{c}=m_{\mathrm{cc}}+m_{\mathrm{un}, 1}-m_{\mathrm{un}, 2} .
\end{gathered}
$$

If the confinement effect is negligible, (6) gives $k_{1}=k_{2}=1$. By comparing (40), (41), and (42) with (47), (45), and (46), respectively, it can easily be observed that $n_{\mathrm{cc}}=n_{\mathrm{un}, 2}$ and $m_{\mathrm{cc}}=m_{\mathrm{un}, 2}$. Therefore, in this case the contributions of the whole section of reacting concrete, given by (48) and (49), are reduced to the values $n_{\mathrm{cc}}=n_{\mathrm{un}, 1}$ and $m_{\mathrm{cc}}=m_{\mathrm{un}, 1}$ and are expressed by (45) and (46) for $k_{1}=k_{2}=1$.

\section{Analysis Procedure}

The flexural response of a class of RC sections, characterized by assigned values of the geometrical and mechanical parameters defined above, is obtained by imposing the equilibrium condition expressed by (15) and (16).

For each configuration the contributions to the equilibrium provided by the principal reinforcement ((23) and (24), under the conditions expressed by (26)), the secondary reinforcement ((28), (35), and (36), under the conditions expressed by (37)), and the compressed region of concrete ((48) and (49), considering (41)-(47)) only depend on the variables $\bar{x}_{c}$ and $\widetilde{\varphi}$, which are independent of or related to one another according to the type of analysis required (see below). In all cases, it must be assumed that the proposed formulation is applied for $\widetilde{\varphi}>0$.

5.1. Field of Application. The field of validity of the procedure proposed here is limited by the fact that the constitutive law of the steel reinforcement does not include unloading branches starting from a point of the post yielding branches in compression or in tension. Therefore, for any loading step the upper principal reinforcement and the upper fibre of the distributed secondary reinforcement, both potentially subject to compression, cannot be in the postyielding field in tension; the lower principal reinforcement and the lower fibre of the distributed secondary reinforcement, both potentially subject to tension, cannot be in the postyielding field in compression.

Because of these assumptions, the field of values of $\bar{x}_{c}$ consistent with a given value of $\widetilde{\varphi}$ is limited by the initial and end values provided by (26) or (37).

More precisely, in the absence of secondary reinforcement $\left(\omega_{2}=0\right)$, (26) gives

$$
\bar{x}_{c, \min }=\lambda-\frac{\zeta_{s, c}}{\widetilde{\varphi}}, \quad \bar{x}_{c, \max }=(1-\lambda)+\frac{\zeta_{s, c}}{\widetilde{\varphi}},
$$

while if the secondary reinforcement is present, (37) leads to more restrictive limitations:

$$
\bar{x}_{c, \min }=\frac{1-\alpha}{2}-\frac{\zeta_{s, c}}{\widetilde{\varphi}}, \quad \bar{x}_{c, \max }=\frac{1+\alpha}{2}+\frac{\zeta_{s, c}}{\widetilde{\varphi}} .
$$

These limitations also occur in a classical numerical approach, based on the strip decomposition of the section.

However, it must be observed that (50) or (51) allows one to construct the moment-curvature curve for a large field of values of assigned level of compression, including the more usual cases occurring in practical applications.

5.2. Moment-Curvature Curves. The more usual application of the analytical expressions derived in the previous sections is to derive by a step-by-step procedure the moment-curvature $m-\widetilde{\varphi}$ curve of a class of RC sections for a given value of $n$.

To this purpose the procedure is applied by the following steps:

(i) assigning the lowest value of curvature $\widetilde{\varphi}$ that one wants to consider, increasing values of $\bar{x}_{c}$ are considered, from the minimum to the maximum expressed by (50) or (51);

(ii) for each value of the couple $\widetilde{\varphi}, \bar{x}_{c}$ the corresponding value of $n_{s 1}, n_{s 2}$, and $n_{c}$ are calculated, and their sum increasing for each increase in $\bar{x}_{c}$;

(iii) when the assigned value of $n$ is reached with an acceptable tolerance (i.e., (15) is verified with very good approximation), the assigned values of $\widetilde{\varphi}$ and $n$, and the value of $\bar{x}_{c}$ that was found, make it possible to calculate the corresponding values of $m_{s 1}, m_{s 2}$, and $m_{c}$ expressed by (24), (36), and (49), and the sum of these contributions of moment is the ordinate of the point having the abscissa $\widetilde{\varphi}$, belonging to the $m-\widetilde{\varphi}$ curve sought;

(iv) considering an increased value of $\widetilde{\varphi}$, the procedure is repeated to obtain a subsequent point of the momentcurvature curve.

The procedure stops when the maximum available ultimate confined concrete strain or the maximum available tensile strain of the lower reinforcement is exceeded. These two occurrences imply, respectively, that $\widetilde{\varphi} \bar{x}_{c}>\mu_{\mathrm{cc}}$ or $\widetilde{\varphi}\left(\bar{x}_{c}-1+\right.$ $\lambda)<-\zeta_{s, c} \mu_{r}$, where $\mu_{\mathrm{cc}}=\varepsilon_{\mathrm{ccu}} / \varepsilon_{\mathrm{cco}}$, is the available ductility of the confined concrete defined in Section 3.1 and $\mu_{r}$ is the steel ductility defined in (11).

If the stress-strain law of the steel reinforcement also exhibits a softening postyielding branch corresponding to a postbuckling behaviour up to the strain value $\varepsilon_{s}^{\bullet}$ (Figure 3), a further limit at which the procedure must be stopped derives from the condition that $\widetilde{\varphi}\left(\bar{x}_{c}-\lambda\right)>\zeta_{s, c} \mu_{r, c}$, in which $\mu_{r, c}=\varepsilon_{s}^{*} / \varepsilon_{s y}$. Beyond this condition the residual stress of the compressed reinforcement should be assumed to be constant and equal to $0.2 f_{s y}$, but this branch of the stressstrain law is not considered in the proposed model, as stated in Section 3.2. 
5.3. Strength and Curvature Domains. A typical $m-\tilde{\varphi}$ curve exhibits two characteristic points corresponding to the achievement of the ultimate state and to the first yielding of the principal reinforcement in tension, respectively. Obviously, the first point is present in all cases, while the second can only be reached if yielding of the reinforcement in tension occurs before the brittle collapse of the concrete core due to low available concrete ductility or/and a very high compression level.

The analytical expressions shown in the previous sections make it possible to determine directly the coordinates of these points and to derive in closed form the $m_{u}-n, \widetilde{\varphi}_{u}-n$ and $m_{y}-n$, $\widetilde{\varphi}_{y}$ - $n$ domains, which give useful information on the flexural strength and curvature ductility of an RC section subjected to an assigned compression level.

The constructions of the aforementioned curves can be made more easily than by using a classical discretized model of the section, because (15) and (16), in a suitable specialized form, provide analytical expressions where the axial compressive load and the corresponding bending moment only depend on a single variable, $\bar{x}_{c}$ and $\tilde{\varphi}$ being related to one another.

In order to construct the $m_{u}-n$ and $\widetilde{\varphi}_{u}-n$ curves, two different relationships linking the neutral axis depth to the curvature must be considered, according to whether the collapse of the section is produced by excess of the available strain of the reinforcement in tension or of the available strain of the concrete core in compression. Moreover, to distinguish these two different events, it must be observed that the maximum curvature of the section is reached when these two conditions occur simultaneously. Considering Figure 4, it can easily be deduced that this value of curvature, in normalized form, is

$$
\widetilde{\varphi}_{u, \max }=\frac{\mu_{\mathrm{cc}}+\zeta_{s, c} \mu_{r}}{1-\lambda}
$$

The first branch of the domains sought is determined by imposing the condition that the collapse of the section is due to the achievement of the maximum tensile strain of the principal reinforcement in tension (low level of compression). Therefore, the following condition has to be assumed:

$$
\tilde{\varphi}_{u}\left(\bar{x}_{c}-1+\lambda\right)=-\zeta_{s, c} \mu_{r} \Longrightarrow \bar{x}_{c}=(1-\lambda)-\frac{\zeta_{s, c} \mu_{r}}{\widetilde{\varphi}_{u}}
$$

Considering increasing values of the curvature from the minimum value to the maximum expressed by (52), the second of (53) provide the corresponding value of $\bar{x}_{c}$, and (15) and (16), by making explicit the contributions of the concrete and the principal and secondary reinforcement, provide the corresponding values of $n$ and $m_{u}$.

Once $\widetilde{\varphi}_{u, \max }$ is reached, the second branch of the $m_{u}-n$, $\widetilde{\varphi}_{u}-n$ curves must be determined considering that, for further decreasing values of $\widetilde{\varphi}_{u}$, the collapse is produced by the achievement of the maximum compressive strain of the confined concrete. Therefore, the new relationship linking the curvature to the neutral axis depth is

$$
\widetilde{\varphi}_{u} \bar{x}_{c}=\mu_{\mathrm{cc}} \Longrightarrow \bar{x}_{c}=\frac{\mu_{\mathrm{cc}}}{\widetilde{\varphi}_{u}}
$$

By using the second of these equations, (15) and (16) again link $n$ and $m_{u}$ to the only variable $\widetilde{\varphi}_{u}$.

It must be observed that, if the principal reinforcement in compression is subject to buckling after the achievement of the yielding stress, the ultimate strain of this compressed reinforcement is the strain denoted as $\varepsilon_{s}^{\bullet}$ in Figure 3. This strain value can be reached before the concrete core reaches the normalized value of strain $\mu_{\mathrm{cc}}$. In this case, the maximum value of normalized dimensionless curvature expressed by (52) must be substituted by the value $\widetilde{\varphi}_{u, \max }=\zeta_{s, c}\left(\mu_{r, c}+\right.$ $\left.\mu_{r}\right) /(1-2 \lambda)$, where $\mu_{r, c}=\varepsilon_{s}^{*} / \varepsilon_{s y}$, and the second branch of the ultimate strength domains must be determined by assuming that for values of $\widetilde{\varphi}_{u}$ that decrease from this maximum the relationship linking the neutral axis dept to the curvature is $\bar{x}_{c}=\lambda+\zeta_{s, c} \mu_{r, c} / \widetilde{\varphi}$.

The $m_{y}-n, \tilde{\varphi}_{y}-n$ curves can be simply determined by assuming that whatever the value of the curvature is, the principal reinforcement in tension is affected by the strain value equal to $-\varepsilon_{s y}$. This condition, in dimensionless terms, gives

$$
\widetilde{\varphi}_{y}\left(\bar{x}_{c}-1+\lambda\right)=-\zeta_{s, c} \Longrightarrow \bar{x}_{c}=(1-\lambda)-\frac{\zeta_{s, c}}{\widetilde{\varphi}_{y}} .
$$

By introducing the second of (55) into the equilibrium Equations (15) and (16), they again become two functions of the single variable $\tilde{\varphi}=\tilde{\varphi}_{y}$. The $m_{y}-n, \widetilde{\varphi}_{y}-n$ curves can be constructed starting from a value that was assumed to be the minimum up to the maximum value corresponding to one of the possible aforementioned occurrences: the collapse of the concrete core, due to achievement of the available ductility of the material, or the achievement of the strain $\varepsilon_{s}^{\bullet}$ in the principal reinforcement in compression, if this reinforcement is subject to buckling.

Considering the field of validity of the procedure proposed, the minimum value of $\widetilde{\varphi}_{u}$ that can be considered to construct the $m_{u}-n, \widetilde{\varphi}_{u}-n$ domains is obtained by introducing the second of (53) into the first of (50) or (51), so that

$$
\widetilde{\varphi}_{u, \min }=\zeta_{s, c} \frac{\mu_{r}-1}{1-2 \lambda},
$$

in the absence of the secondary reinforcement, and

$$
\widetilde{\varphi}_{u, \min }=\zeta_{s, c} \frac{\mu_{r}-1}{(1+\alpha) / 2-\lambda},
$$

if the secondary reinforcement is also present.

Obviously, the $m_{y}-n, \widetilde{\varphi}_{y}-n$ domains can be constructed starting from any value $\widetilde{\varphi}_{y}>0$.

In relation to the field of applications ( $\mathrm{RC}$ columns), the first values of $\widetilde{\varphi}_{u}$ and $\widetilde{\varphi}_{y}$ that are to be actually considered are the ones first producing $n \geq 0$.

\section{Applications}

The reliability of the procedure proposed is shown here by using the results derived from two RC sections considered by other researchers.

The first application refers to one of the sections examined by Zahn et al. [27]. This was a square RC section of side $B=400 \mathrm{~mm}$ and realized with concrete having cylindrical 


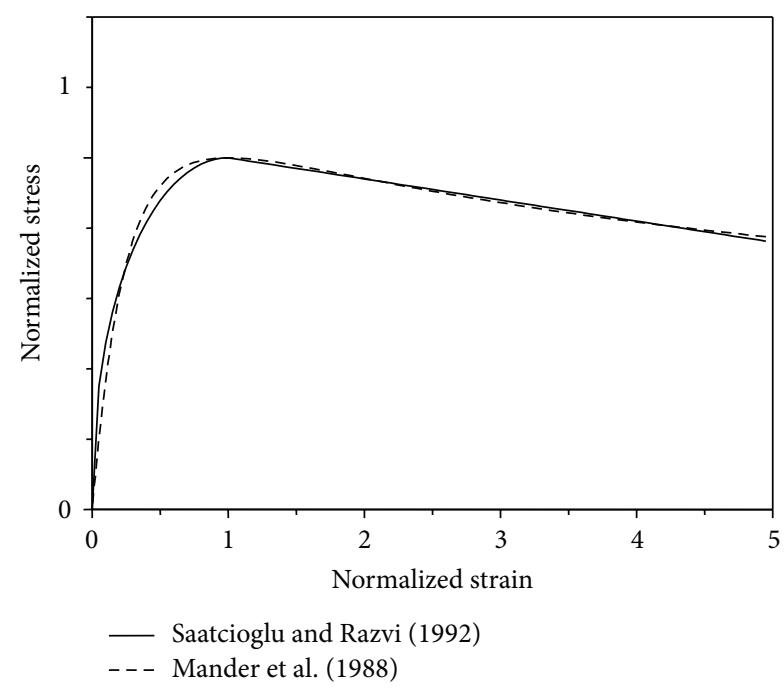

Figure 7: Calibration of constitutive law of confined concrete.

strength $f_{\text {co }}=30 \mathrm{~N} / \mathrm{mm}^{2}$. The longitudinal reinforcement consisted of 12 steel bars of diameter $16 \mathrm{~mm}$, having yielding strength $f_{s y}=420 \mathrm{~N} / \mathrm{mm}^{2}$, uniformly distributed along the perimeter of the concrete core (constant pitch). The cover depth, measured from the external perimeter of the stirrups, was $13 \mathrm{~mm}$. The transverse reinforcement, consisting of steel stirrups of diameter equal to $10 \mathrm{~mm}$, according to the calculations made by the aforementioned authors, provided the effective confinement pressure $f_{l e}=0.11 f_{\mathrm{co}}^{\prime}$, where $f_{\mathrm{co}}^{\prime}=$ $0.85 f_{\text {co }}$ is the reduced strength value prescribed by the ACI 318 code [28].

The flexural response was numerically derived in [27] by using a classical fibre model in which the stress-strain law of the confined concrete was assumed in agreement with Mander's model [25]. Therefore, in this application the parameters $\beta_{\mathrm{cc}}$ and $\eta_{\mathrm{cc}}$, governing the shape of the laws expressed by (4) and (5), are calibrated so that they lead to a constitutive law of confined concrete which is very similar to that used by the aforementioned authors.

Mander's model [25] for the given value of the confinement pressure is governed by the parameter $r=1.3$; the model of Saatcioglu and Razvi [18] leads to a very similar shape of the stress-strain curve by assuming that $\beta_{c c}=0.45$ and $\eta_{c c}=-0.06$. Figure 7 shows the very similar shapes of the constitutive laws corresponding to the two models considered.

The procedure proposed in [25] provided the following characteristic values of confined concrete strength and corresponding strain: $\varepsilon_{\text {cco }}=0.0073, f_{\text {cco }}=46 \mathrm{~N} / \mathrm{mm}^{2}$. These values are also adopted for the dimensional stress-strain law expressed by the model used here [18].

Since for the stress-strain law of the unconfined concrete Zahn et al. [27] do not give any information, the default values indicated in Section 3.1 are assumed here: $\beta_{c}=1, \eta_{c}=-0.8$, and $\varepsilon_{\mathrm{co}}=0.002$.

On the basis of the above data, the square cross-section of the concrete core, measured inside the perimeter stirrups, has a side of $b=h=354 \mathrm{~mm}$; the cover depth is equal to

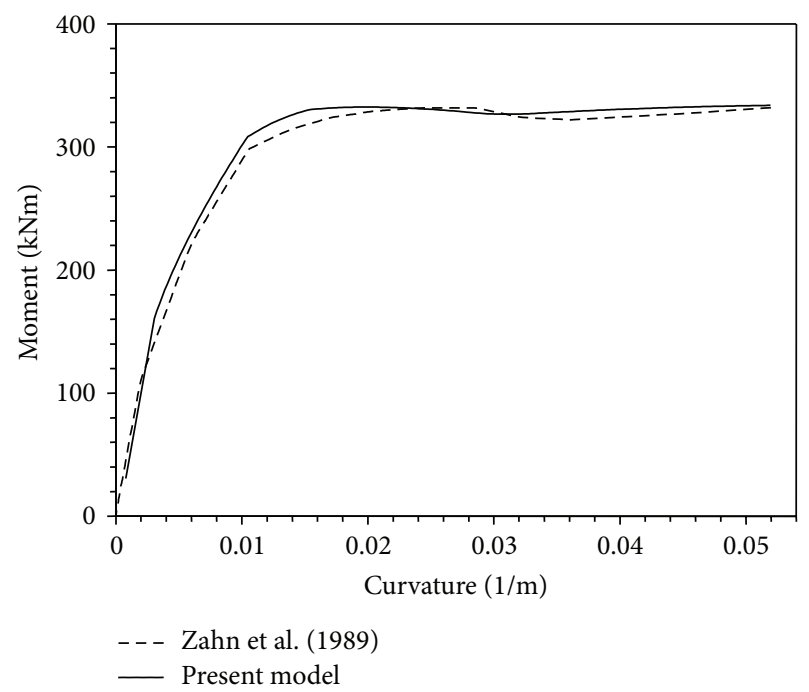

FIgURE 8: Comparison of results: $M-\varphi$ curve for given $N$.

$23 \mathrm{~mm}$, the number of intermediate reinforcing bars realizing the secondary reinforcement is $n_{b}=n_{h}=2$, and the distance of the barycentre of the section of the principal reinforcement from the external side of the concrete core section is $h_{1}=$ $16 / 2=8 \mathrm{~mm}$.

The principal reinforcement consists of four upper and four lower $16 \mathrm{~mm}$ steel bars while the secondary reinforcement consists of four bars (two on the right and two on the left) of the same diameter. The steel reinforcement constitutive law is defined by assuming $E_{s}=210 \mathrm{GPa}, \varepsilon_{s y}=f_{s y} / E_{s}=$ $0.002)$ and $E_{s h}=E_{s c}=0$.

Therefore, the dimensionless parameters involved in the formulation proposed take on the following values: $\delta_{v}=\delta_{o}=$ $23 / 354=0.065, \lambda=8 / 354=0.0226, \alpha=0.6365, \zeta_{s, c}=$ $0.002 / 0.0073=0.274, k_{1}=46 / 30=1.53, k_{2}=0.0073 /$ $0.002=3.65, \omega_{1}=0.117, \omega_{2}=\omega_{1} / 2$, and $\eta_{s c}=\eta_{s h}=0$.

Figure 8 compares the $M-\varphi$ curve obtained in [27] with that derived from the procedure shown in Section 5.2 for a compressive constant axial load $N=0.3 f_{\text {co }}(B \times B)$, corresponding to a compressive level $n=N /\left(b^{2} \times f_{\text {cco }}\right)=0.25$, in agreement with the first of (14). The results in the figure show a very good level of agreement between the numerical procedure adopted in [27] and the analytical one adopted here.

Both curves in the figure clearly show the cusp produced by the yielding of the principal reinforcement in tension and the effects of the progressive cover spalling.

The second application refers to the middle-height section of an RC column, of height $1640 \mathrm{~mm}$, experimentally tested by Saatcioglu et al. [19], marked as specimen C6-2 by the authors.

The loading condition was realized by imposing relative axial displacements so that the reactive compressive force acted with fixed eccentricity in a plane of principal inertia of the sections. Suitable devices were applied at the column ends so that the column itself behaved like a hinged vertical $\mathrm{RC}$ member under an eccentric compressive load.

As a consequence, each point of the moment-curvature curve characterizing the experimental response obtained by 
the aforementioned authors corresponds to a different value of axial load. Moreover, the actual bending moment acting on the middle-height section was influenced by the $P-\Delta$ effect.

The formulation proposed here is validated considering some points of the aforementioned curve for which the authors indicate the values of the axial load $N$ and curvature that were measured. These values of $N$ are normalized with respect to the axial load $N_{o}$ expressed by (2). The procedure is applied by determining the value of $\bar{x}_{c}$ from (15) for the assigned values of $n$ and $\widetilde{\varphi}$ and by calculating $m$ from (16). The results are compared with the numerical values obtained by the strip model adopted by the authors, which included the $P-\Delta$ effect and the values experimentally detected.

The specimen considered had a square section of side $B=$ $210 \mathrm{~mm}$, cover depth of $12.5 \mathrm{~mm}$ and longitudinal reinforcing bars of diameter $11.3 \mathrm{~mm}$, uniformly distributed along the perimeter of the concrete core, having yielding strength $f_{s y}=$ $517 \mathrm{~N} / \mathrm{mm}^{2}$ and average hardening modulus $E_{s h}=0.013 E_{s}$. The transverse steel reinforcement consisted of square and octagonal $6.3 \mathrm{~mm}$ stirrups with pitch $50 \mathrm{~mm}$.

The unconfined concrete had cylindrical strength $f_{\text {co }}=$ $34.40 \mathrm{~N} / \mathrm{mm}^{2}$. The numerical model adopted in [19] assumed that the perimeter of the concrete core was coincident with the axis lines of the external stirrups.

On the basis of these geometrical and mechanical data, and by evaluating the effective confinement pressure by the procedure proposed in [18], for the confined concrete section one obtains $b=h=178.70 \mathrm{~mm}, f_{\text {cco }}=46.35 \mathrm{~N} / \mathrm{mm}^{2}, \varepsilon_{\text {cco }}=$ $0.00547, \eta_{\mathrm{cc}}=-0.052$, and $\beta=0.590$. The further parameters involved in the formulation proposed take on the following values: $\delta_{o}=\delta_{v}=0.087, \lambda=0.0492, \alpha=0.601, \zeta_{s, c}=0.4724$, $k_{1}=1.347, k_{2}=2.735, \omega_{1}=0.280, \omega_{2}=\omega_{1} / 2$, and $\eta_{s c}=$ $\eta_{s h}=0.013$.

Figure 9 shows that the procedure proposed provides results that are very close to those derived by the numerical model adopted in [19]. The experimentally detected values of moment prove to be underestimated by both models.

It must be observed that the last point detected by using the present formulation, corresponding to the ultimate state of the section, had been already found in [17], because this section belongs to the more restricted class of sections considered in that work.

Figure 10 shows the strength and curvature domains obtained by using the procedure described in Section 5.3. For confined concrete and steel reinforcement the following values were assumed, deduced from the data shown in [19]: $\varepsilon_{\text {ccu }}=0.032\left(\mu_{\mathrm{cc}}=5.85\right)$ and $\varepsilon_{s u}=0.066\left(\mu_{r}=27\right)$. The results confirm that a good level of confinement makes it possible to achieve acceptable ductility of curvature even under high levels of compression. In order to show how the procedure proposed is easily able to evaluate the influence of all the geometric and mechanical parameters governing the flexural response of a class of RC sections, Figure 10(a) also shows the influence of the unconfined concrete cover on the bending moment at the first yielding of the principal reinforcement in tension. As expected, this influence proves to be negligible for high values of the compression level.

The dotted curve in Figure 10(b) obviously stops at the point of intersection with the continuous curve. Beyond this

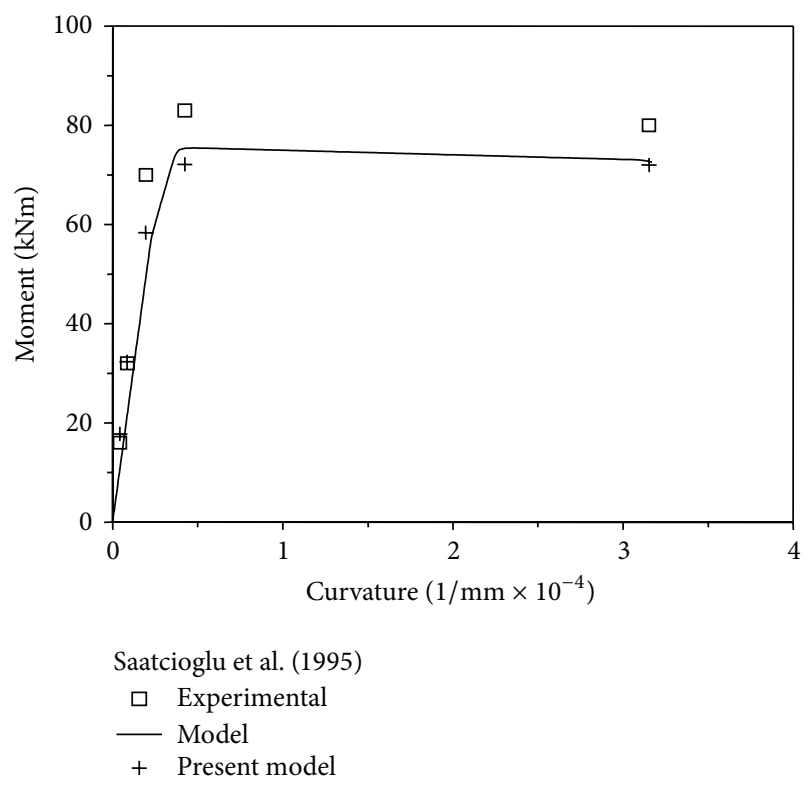

Figure 9: Comparison of theoretical and experimental results.

point the $\varphi_{u}-N$ curve proceeds by a very brief stretch (not very evident in the figure) that corresponds to brittle collapse of the section due to the achievement of the maximum available compressive strain in the confined concrete when the principal reinforcement in tension is still in the elastic field. The end point of this curve corresponds to the achievement of the maximum neutral axis depth defined by the second of (51).

Nevertheless, the axial load values that cannot be considered because of these limitations are well beyond the ones that can be assumed in the structural design of RC buildings in seismic areas or usually found in the columns of existing buildings.

\section{Conclusions}

A dimensionless formulation has been proposed, which provides the flexural response of classes of sections of RC columns having the same values of the geometric and mechanical parameters defined in this study.

At each loading stage, the resisting components of the section (cover and concrete core and principal and secondary longitudinal reinforcements) give a contribution to the equilibrium that can be expressed by analytical functions depending on the normalized neutral axis depth and the curvature of the section.

Special equilibrium conditions, like the ones corresponding to the first yielding of the principal reinforcement in tension and to the ultimate state, imply an analytical link between the neutral axis depth and the curvature, so that the sum of the aforementioned contributions becomes an analytical function of a single variable, which can express a strength or curvature domain.

For a generic equilibrium condition an iterative procedure to determine the neutral axis depth corresponding to 


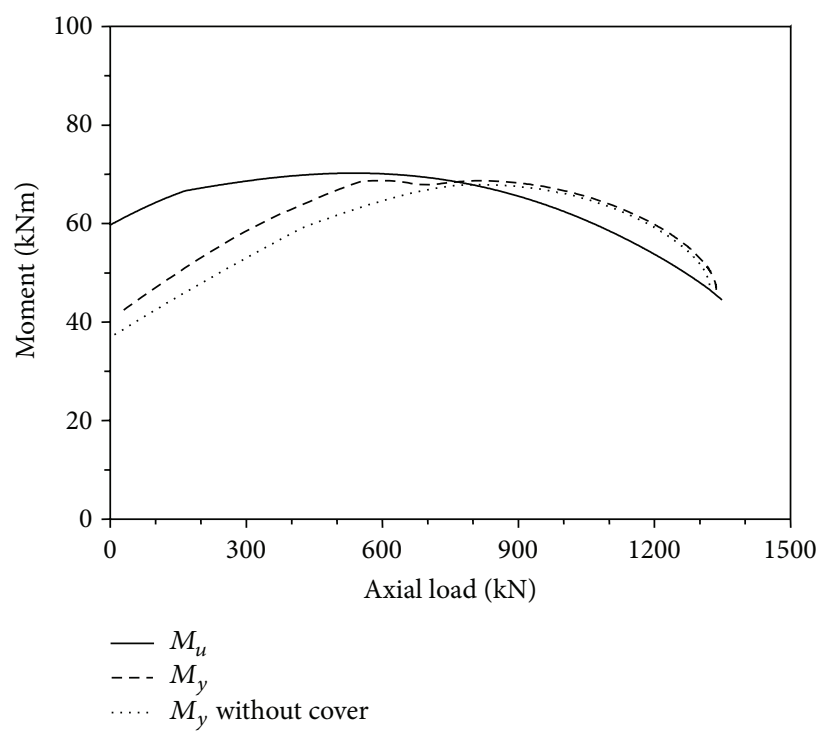

(a)

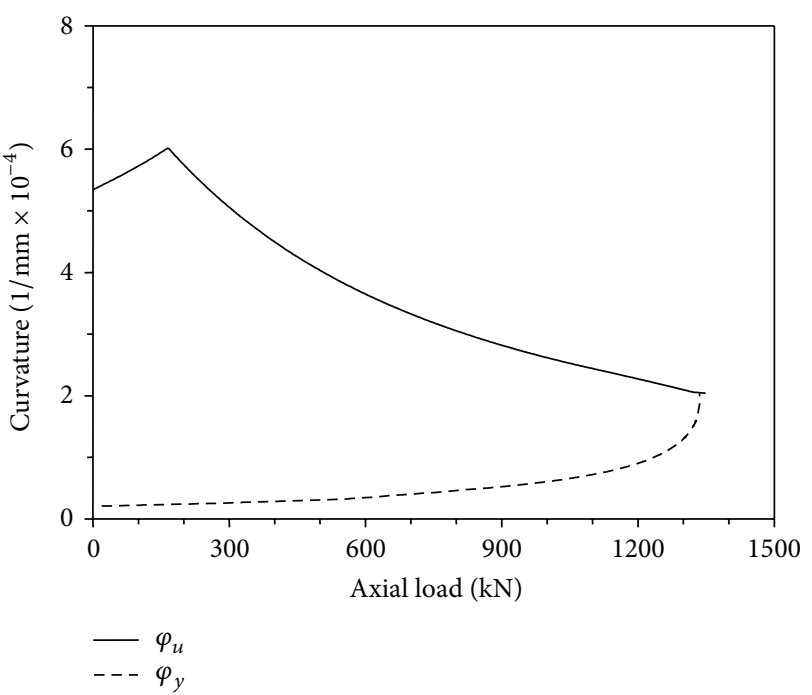

(b)

Figure 10: $M-N$ and $\varphi-N$ domains at the ultimate state and the first yielding of reinforcement.

the assigned values of curvature and compression level is required, but each iteration step implies the simple use of the same equilibrium equation for an updated value of the normalized neutral axis dept.

The dimensionless form of the formulation proposed makes also it easily possible to evaluate the influence of the parameters characterizing the class of sections examined on the strength and curvature corresponding to a given loading stage.

\section{Acknowledgment}

This work was carried out within the 2010-2013 Research Project "DPC-ReLUIS (Dipartimento Protezione Civile-Rete dei Laboratori Universitari di Ingegneria Sismica)," AT 1, Task 1.1.2. The related financial support was greatly appreciated.

\section{References}

[1] A. Fafitis, "Interaction surfaces of reinforced-concrete sections in biaxial bending," Journal of Structural Engineering, vol. 127, no. 7, pp. 840-846, 2001.

[2] J. L. Bonet, P. F. Miguel, M. A. Fernandez, and M. L. Romero, "Analytical approach to failure surfaces in reinforced concrete sections subjected to axial loads and biaxial bending," Journal of Structural Engineering, vol. 130, no. 12, pp. 2006-2015, 2004.

[3] G. Monti and S. Alessandri, "Assessment of rc columns under combined biaxial bending and axial load," in Proceedings of the 2nd FIB Congress, Naples, Italy, 2006.

[4] R. W. Clough and S. B. Johnston, "Effect of stiffness degradation on earthquake ductility requirements," in Proceedings of $2 \mathrm{nd}$ Japan Earthquake Engineering Symposium, Tokyo, Japan, 1966.

[5] T. Takeda, M. A. Sozen, and N. N. Nielsen, "Reinforced concrete response to simulated earthquake," Journal of Structural Division, vol. 96, no. 12, pp. 2257-2273, 1970.
[6] M. S. L. Roufaiel and C. Meyer, "Analytical modeling of hysteretic behavior of reinforced concrete frame," Journal of Structural Engineering, vol. 113, no. 3, pp. 429-444, 1987.

[7] A. R. Mari and A. C. Scordelis, "Nonlinear geometric, material and time dependent analysis of three dimensional reinforced and prestressed concrete frames," USB/SESM Report 84/12, Department of Civil Engineering, University of California, Berkeley, Calif, USA, 1973.

[8] T. Taucer, E. Spacone, and F. C. Filippou, "A fiber beam-column element for seismic response analysis of reinforced concrete structures," Report EERC 91-17, Earthquake Engineering Research Center, Berkeley, Calif, USA, 1991.

[9] Z. Zhu, I. Ahmad, and A. Mirmiran, "Fiber element modeling for seismic performance of bridge columns made of concretefilled FRP tubes," Engineering Structures, vol. 28, no. 14, pp. 2023-2035, 2006.

[10] E. O. Pfrang, C. P. Siess, and M. A. Sozen, "Load-moment-curvature characteristics of RC cross-sections," ACI Journal, vol. 61, no. 7, pp. 763-778, 1964.

[11] D. J. Carreira and K.-H. Chu, "The moment-curvature relationship of RC members," ACI Journal, vol. 83, no. 2, pp. 191-198, 1986.

[12] R. H. Wood, "Some controversial and curious developments in plastic theory of structures," in Engineering Plasticity, J. Heyman and F. A. Leckie, Eds., pp. 665-691, Cambridge University Press, Cambridge, UK, 1968.

[13] Y. L. Mo, "Investigation of reinforced concrete frame behaviour: theory and tests," Magazine of Concrete Research, vol. 44, no. 160, pp. 163-173, 1992.

[14] M. Jirasek and Z. P. Bazant, Inelastic Analysis of Structures, Jon Wiley \& Sons, London, UK, 2002.

[15] S. Chandrasekaran, L. Nunziante, G. Serino, and F. Carannante, "Curvature ductility of RC sections based on Eurocode: analytical procedure," KSCE Journal of Civil Engineering, vol. 15, no. 1, pp. 131-144, 2011. 
[16] M. Fossetti and M. Papia, "Dimensionless analysis of RC rectangular sections under axial load and biaxial bending," Engineering Structures, vol. 44, pp. 34-45, 2012.

[17] P. Colajanni, M. Fossetti, and M. Papia, "Analytical prediction of ultimate moment and curvature of RC rectangular sections in compression," Bulletin of Earthquake Engineering, 2013.

[18] M. Saatcioglu and S. R. Razvi, "Strength and ductility of confined concrete," Journal of Structural Engineering, vol. 118, no. 6, pp. 1590-1607, 1992.

[19] M. Saatcioglu, A. H. Salamat, and S. R. Razvi, "Confined columns under eccentric loading," Journal of Structural Engineering, vol. 121, no. 11, pp. 1547-1556, 1995.

[20] G. Campione, M. Fossetti, and M. Papia, "Simplified analytical model for compressed high-strength columns confined by transverse steel and longitudinal bars," in Proceedings of the 2nd FIB Congress, Naples, Italy, 2006.

[21] G. Campione, M. Fossetti, and M. Papia, "Behavior of fiber-reinforced concrete columns under axially and eccentrically compressive loads," ACI Structural Journal, vol. 107, no. 3, pp. 272281, 2010.

[22] G. Campione, M. Fossetti, G. Minafò, and M. Papia, "Influence of steel reinforcements on the behavior of compressed high strength R.C. circular columns," Engineering Structures, vol. 34, pp. 371-382, 2012.

[23] E. Hognestad, A Study of Combined Bending and Axial Load in Reinforced Concrete Members, Bulletin Series No. 399, Engineering Experiment Station, University of Illinois, Urbana, Ill, USA, 1951.

[24] B. D. Scott, R. Park, and M. J. N. Priestley, "Stress-strain behaviour of concrete confined by overlapping hoops at low and high strain rate," ACI Journal, vol. 79, no. 2, pp. 13-27, 1982.

[25] J. B. Mander, M. J. N. Priestley, and R. Park, "Theoretical Stressstrain model for confined concrete," Journal of Structural Engineering, vol. 114, no. 8, pp. 1804-1826, 1988.

[26] R. P. Dhakal and K. Maekawa, "Modeling for postyield buckling of reinforcement," Journal of Structural Engineering, vol. 128, no. 9, pp. 1139-1147, 2002.

[27] F. A. Zahn, R. Park, and M. J. N. Priestley, "Strength and ductility of square reinforced concrete column sections subjected to biaxial bending," ACI Structural Journal, vol. 86, no. 2, pp. 123131, 1989.

[28] Building Code Requirements for Structural Concrete and Commentary, ACI 318, American Concrete Institute (ACI), 2008. 

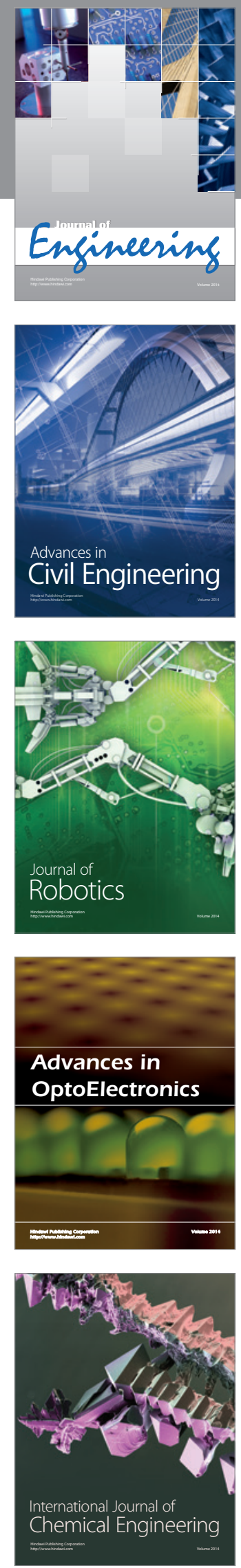

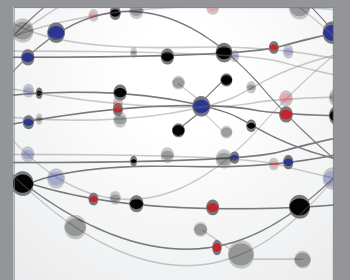

The Scientific World Journal
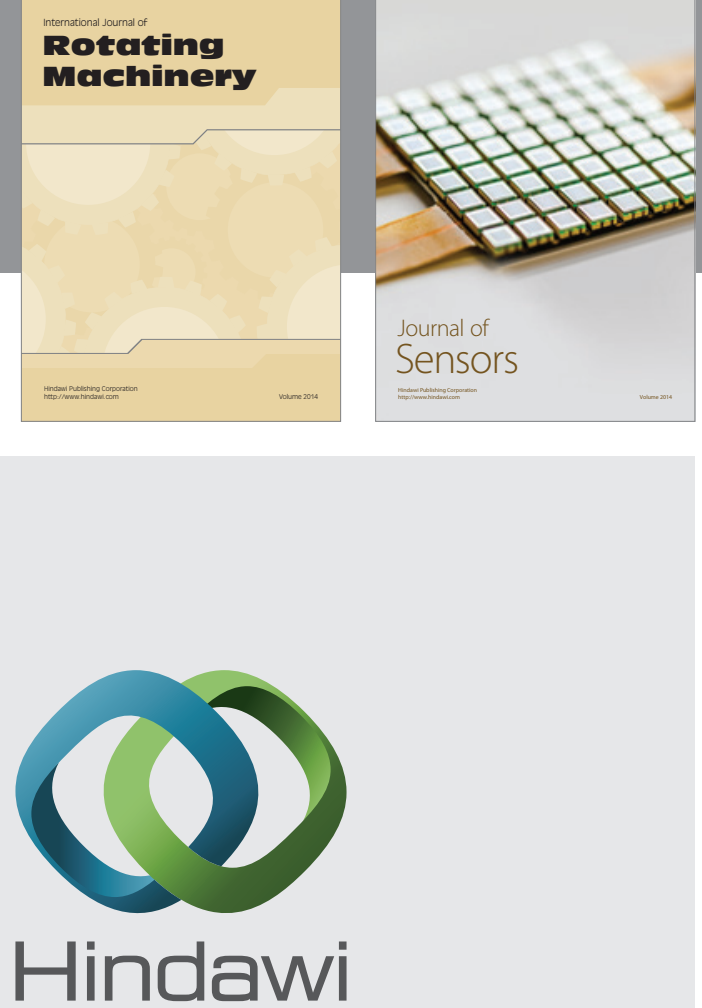

Submit your manuscripts at http://www.hindawi.com
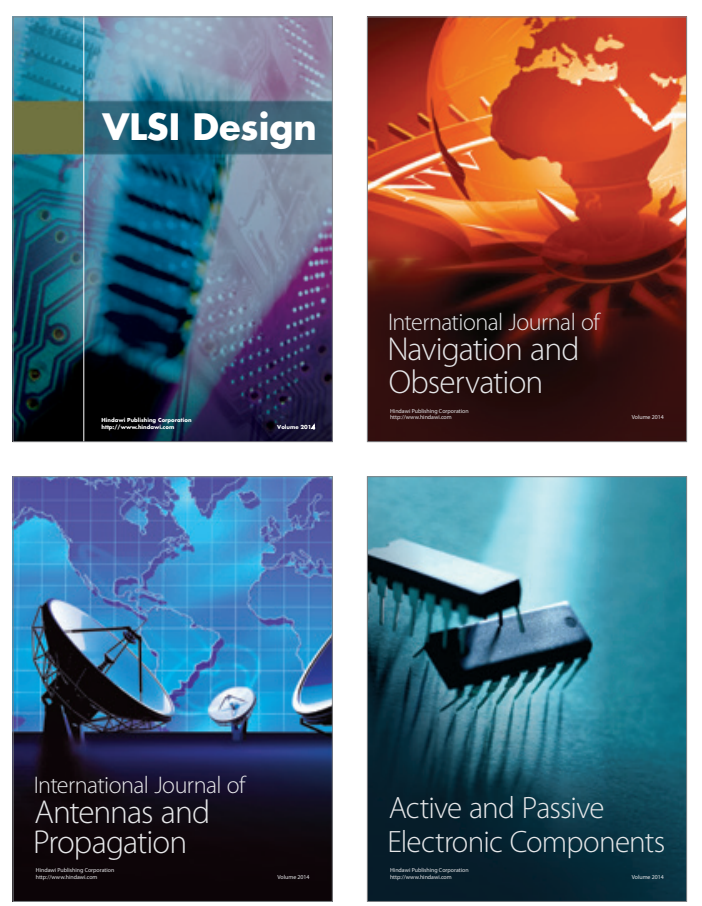
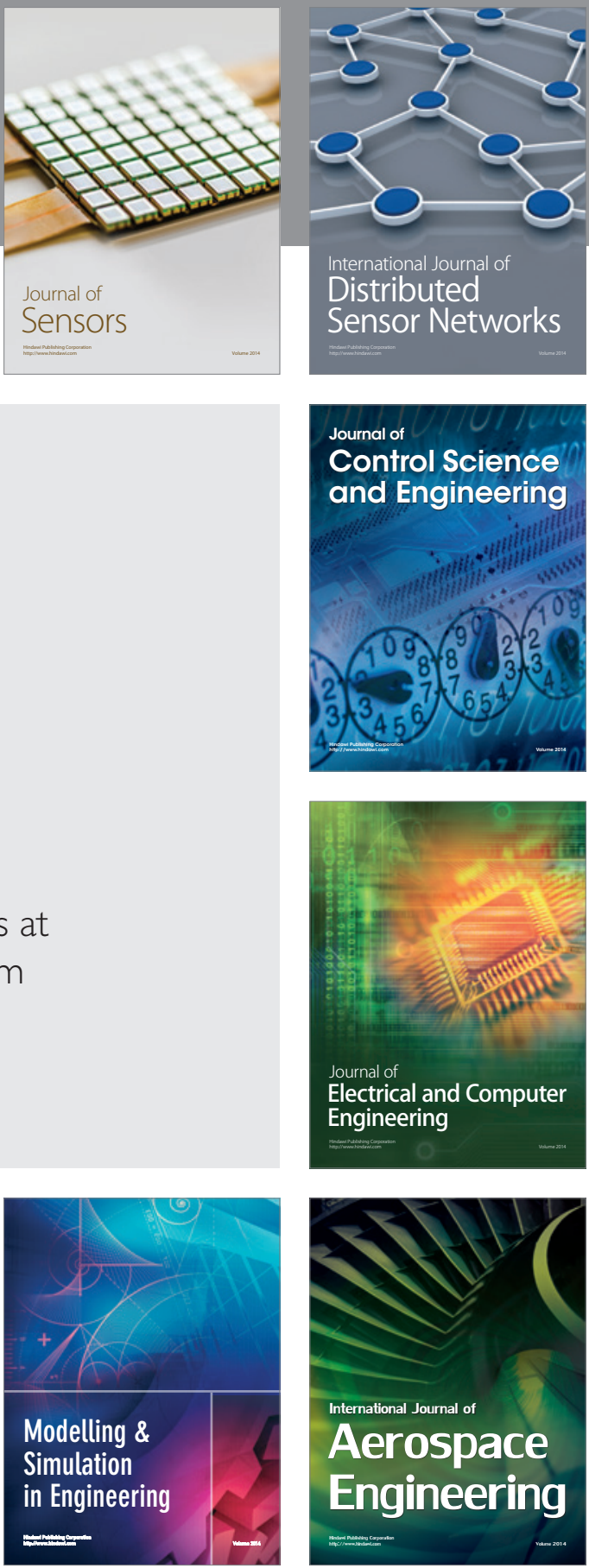

Journal of

Control Science

and Engineering
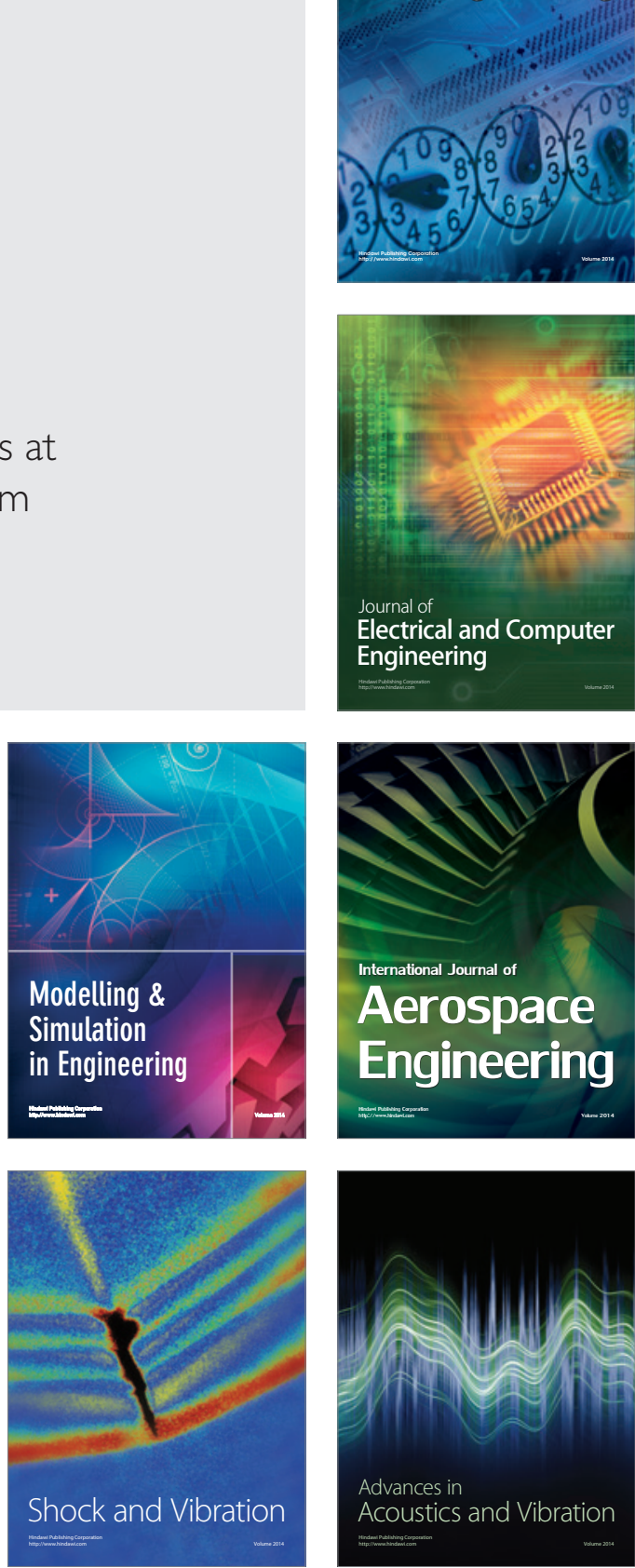